\title{
Prevalence of Dental Caries among Children in Indian Population
}

\author{
John Ebinezer ${ }^{1}$, Vezhavendhan Nagaraj ${ }^{2}$
}

\begin{abstract}
Introduction: Dental caries plays an important role in oral health problems. Its prevalence and severity is increasing day by day throughout the world. Thus, the objective of this review is to analyze the prevalence of dental caries among school-going children in Indian population.

Materials and methods: Three relevant articles were selected for the review, and the articles were searched from PubMed, Embase, Google Scholar, Chinese Biomedical Database, Scopus, and Web of Science.

Results: The prevalence of dental caries among Indian school-going children in primary dentition ranges from 64 to $78 \%$, and in permanent dentition, the value ranges from 18 to $67 \%$. Female had higher caries incidence than male. Prevalence of $61.8 \%$ noticed in low-socioeconomic group and $49.1 \%$ in high-socioeconomic status people.

Conclusion: The prevalence of dental caries among Indian school-going children is high in primary dentition when compared with the permanent dentition, and the caries prevalence rate is high in females. The people from low-socioeconomic status group show higher percentage of caries prevalence.

Keywords: Children, Dental caries, Prevalence of dental caries, Primary dentition.

Journal of Scientific Dentistry (2021): 10.5005/jp-journals-10083-0923
\end{abstract}

\section{INTRODUCTION}

Dental caries plays an important role in oral health problems; its prevalence and severity is increasing day by day throughout the world. Dental caries is a multifactorial disease which commonly affects children of all age groups, due to changing lifestyle, food patterns, increased in intake of carbohydrate, and decrease in exposure to fluoride. ${ }^{3}$

The needful treatment for this age group is restorative care and sometimes pulp therapy. But the more acceptable and economical treatment option is "Prevention." This creates the impact to analyze the prevalence of dental caries among school-going children. Dental caries if left untreated, affects the child's quality of life, school performance, nutrition, decreased weight gain, and premature loss of primary molars affects arch space, which leads to crowding of permanent dentition ${ }^{1,3}$

Dental caries prevalence is closely associated with the region where the resources are inadequate for dental treatment, lack of awareness and motivation, low socioeconomic status, people with poor oral hygiene, and decreased level of parental education. ${ }^{4}$ Thus, the objective of this review is to analyze the prevalence of dental caries among school-going children in Indian population. ${ }^{1}$

\section{Materials and Methods}

Searching and identification of literature was done in PubMed, Embase, Google Scholar, Chinese Biomedical Database, Scopus, and Web of Science. Keywords used were prevalence of dental caries, caries in children, and dental caries.

In total, 15 articles were received from PubMed, Embase, Google Scholar, Chinese Biomedical Database, Scopus, and Web of Science.
1,2Department of Oral Pathology, Indira Gandhi Institute of Dental Sciences, Sri Balaji Vidyapeeth, Puducherry, India

Corresponding Author: John Ebinezer, Department of Oral Pathology, Indira Gandhi Institute of Dental Sciences, Sri Balaji Vidyapeeth, Puducherry, India Phone: +91 9080504638, e-mail: johnebinezer8@ gmail.com

How to cite this article: Ebinezer J, Nagaraj V. Prevalence of Dental Caries among Children in Indian Population. J Sci Dent 2021;11(1): 29-30.

Source of support: Nil

Conflict of interest: None

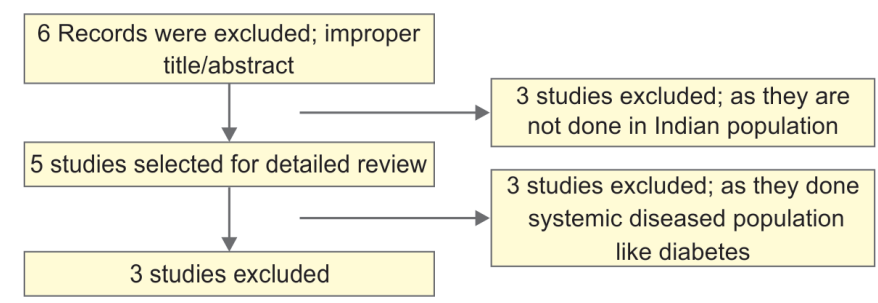

\section{Results and Discussion}

Three articles were analyzed to know the prevalence of dental caries in children of Indian population. Reddy et al. carried out a crosssectional study in the region of Mahbubnagar District, Telangana state, India, with sample size of 2,000 school-going children from rural and urban areas of age group 6-12 years. In that male were 1,021 , and female were 979 . In this total population, 332 of them belong to the age group of 6-7 years and 286 of them belong to the age group of 9-10 years. The assessment of dental caries was done using Decay Missing Filled Teeth (DMFT/dmft) index with the 
World Health Organization (WHO) criteria 1997. The data show that the prevalence of dental caries in primary dentition of male was $63.6 \%$ and female $66.1 \%$ with no statistical significant difference among male and female. The total caries percentage in all gender is $64.2 \%$. The caries prevalence in permanent dentition was $26.2 \%$ in male and $73.5 \%$ in female. The total caries prevalence in both male and female is $26.6 \%$. Here there is a statistical significant difference among male and female, where female prevalence percentage is high. The prevalence of dental caries was higher in primary dentition when compared with permanent dentition. It is due to low calcium content of deciduous teeth. The low-socioeconomic status children are more susceptible to dental caries because of their poor oral hygiene practice, lack of awareness, and improper food intake, and the increased prevalence of caries in female is due to marked preference to the sons and negligence of females in rural areas. ${ }^{1,5,6}$

A descriptive type of epidemiological study carried out in the region of Vaishali, Bihar, India, done by Goenka et al. with a sample size of 1,000 school-going children of 5-13 years age group was examined to find the prevalence of dental caries. In this study population, 312 children were belonging to $5-7$ years age group, 353 children belonging to $8-10$ years age group, 335 children belonging to 11-13 years age group. Out of 1,000 children, males were 501 and females were 499 . The examination procedure and criteria were those recommended by $\mathrm{WHO}$. The data show that caries prevalence in 5-7 years age group was found to be $65.1 \%$, whereas $8-10$ years age group was $56.7 \%$ and $11-13$ years age group was $45.4 \%$. Thus, the prevalence of caries decreased as the age advanced. This is due to the fact that there is increased awareness of oral hygiene with age. The prevalence rate among gender was found to be $59.3 \%$ in males and $51.7 \%$ in females. The difference in prevalence of caries among gender has been found to be statistically significant. According to the location, the prevalence of dental caries in the urban population was $58.9 \%$, whereas in the rural population, it was $51.4 \%$. The high caries prevalence in the urban population is due to accessibility to food items rich in refined sugar and reduced intake of coarse food in their diet, and the prevalence value was $61.8 \%$ in low-socioeconomic status group. The difference was found to be highly significant statistically. $2,7,8$

Another cross-sectional study was done in Belagavi, Karnataka, India, by Anand Hireman et al. with a sample size of 13,200 children, i.e., the Belagavi district was divided into 11 talukas, 1,200 children were randomly selected from each taluk. There are 200-300 primary schools in each taluk comprising of all strata like urban, peri-urban, and rural. The data from a self-designed screening form based on WHO oral health assessment shows that caries prevalence is high in primary dentition was high in 8-9-year-old schoolchildren, and in permanent dentition it was high in 10-11-year-old children. Thus, the study revealed the overall prevalence of dental caries in primary teeth among 6-11-year-old schoolchildren was $78.9 \%$. This prevalence rate is higher when compared with caries prevalence in other countries like Sri Lanka (65.3\%), China (41\%), South Africa (39.7\%), and the United States (41\%). 3,9,10

\section{Conclusion}

The prevalence of dental caries among Indian school-going children was high in primary dentition, when compared with permanent dentition, and there is a statistical significant difference among males and females, where female prevalence percentage is high.

Also, there is no statistical significant difference in the rate of caries prevalence among rural and urban areas, whereas for the low-socioeconomic status people, prevalence percentage is higher, when compared with the high-socioeconomic status people.

\section{References}

1. Reddy KS, Reddy S, Ravindhar P, Balaji K, Reddy H, Reddy A. Prevalence of dental caries among 6-12 years school children of Mahbubnagar district, Telangana State, India: a cross-sectional study. Indian J Dent Sci 2017;9(1):1.

2. Goenka P, Dutta S, Marwah N, Sarawgi A, Nirwan M, Mishra P. Prevalence of dental caries in children of age 5 to 13 years in district of Vaishali, Bihar, India. Int J Clin Pediatr Dent. 2018;11(5):359. DOI: 10.5005/jp-journals-10005-1540.

3. Hiremath A, Murugaboopathy V, Ankola AV, Hebbal M, Mohandoss S, Pastay P. Prevalence of dental caries among primary school children of India-a cross-sectional study. J Clin Diagnos Res 2016;10(10):ZC47. DOI: 10.7860/JCDR/2016/22474.8642.

4. Herrera SM, Medina-Solis CE, Maupomé G. Prevalence of dental caries in 6-12-year-old schoolchildren in Leon, Nicaragua. Gac. Sanit. 2005;19(4):302-306. DOI: 10.1157/13078040.

5. Alhabdan YA, Albeshr AG, Yenugadhati N, Jradi H. Prevalence of dental caries and associated factors among primary school children: a population-based cross-sectional study in Riyadh, Saudi Arabia. Environ. Health Prev. Med. 2018;23(1):60. DOI: 10.1186/s12199-0180750-z.

6. Anil S, Anand PS. Early childhood caries: prevalence, risk factors, and prevention. Front Pediatr. 2017;5:157. DOI: 10.3389/fped.2017.00157.

7. Wang $Y$, Xing $L, Y u H$, Zhao L. Prevalence of dental caries in children and adolescents with type 1 diabetes: a systematic review and meta-analysis. BMC Oral Health 2019;19(1):213. DOI: 10.1186/s12903019-0903-5.

8. Musinguzi N, Kemoli AM, Okullo I. Prevalence and treatment needs for early childhood caries among 3-5-year-old children from a rural community in Uganda. frontiers In. Public Health 2019;7:259.

9. Nomura Y, Maung K, Khine K, Min E, Sint KM, Lin MP, et al. Prevalence of dental caries in 5-and 6-year-old Myanmar children. Int. J. Dent. 2019(1):1-7. DOI: 10.1155/2019/5948379.

10. Mukouyama C, Koike Y, Hirohara T. Transitional changes in the prevalence of dental caries in children and preventive strategies: a review of nationwide annual surveys in Japan. Oral Health Prev Dent. 2018;16(2):107-111. DOI: 10.3290/j.ohpd.a40325. 